\title{
A investigação em turismo em Portugal: um contributo para a sua caracterização
}

\section{Tourism research in Portugal: a contribution to its characterization}

\section{Investigación en turismo en Portugal: una contribución para su caracterización}

\section{João Albino Silva ${ }^{1}$ Patrícia Oom do Valle}

Resumo: Este trabalho pretende ser um primeiro contributo para a caracterização da investigação em Turismo em Portugal, focando a sua atenção no perfil do investigador e nas características da investigação. Para o efeito e tendo por base uma rede de investigadores em Turismo em Portugal, foi possível identificar 166 investigadores a trabalhar nesta área, distribuídos por cerca de 30 instituições de ensino superior, posteriormente convidados a preencher um questionário online. A fase de recolha de dados, em Março de 2013, permitiu obter 111 respostas válidas cuja análise se apresenta neste estudo. Os resultados evidenciam uma comunidade científica predominantemente jovem e em crescimento e sublinham igualmente uma diversa, sólida e estimulante perspectiva disciplinar.

Palavras chave: Investigação em Turismo; Perfil; Temáticas; Tendências.

Abstract: This work intends to be a first contribution to the characterization of tourism research in Portugal, focusing on the researcher's profile and the characteristics of research. To that end, and based on a national Tourism Research, it was possible to identify 166 researchers working in this area, spread over about 30 higher education institutions, who subsequently completed an online questionnaire. Data were collected during March 2013 and 111 valid responses were obtained. The results show a growing and predominantly young scientific community and also highlight a diverse, solid and stimulating disciplinary perspective.

Keywords: Tourism Research; Profile; Themes; Trends

Resumen: Este trabajo pretende ser una primera contribución a la caracterización de la investigación sobre el turismo en Portugal, centrando su atención en el perfil del investigador y las características de la investigación. Para ello, y sobre la base de una red de investigadores en el sector turístico de Portugal, fue posible identificar 166 investigadores que trabajan en esta área, repartidos en cerca de 30 instituciones de educación superior, posteriormente invitados a completar un cuestionario en línea. La fase de recolección de datos produjo 111 respuestas válidas cuyo análisis se presenta en este estudio. Los resultados muestran

\footnotetext{
${ }^{1}$ Faculdade de Economia Universidade do Algarve, Portugal. E-mail: jsilva@ualg.pt

${ }^{2}$ Faculdade de Economia Universidade do Algarve, Portugal. E-mail: pvalle@ualg.pt
} 
una comunidad científica predominantemente joven y en crecimiento, y también destacan una perspectiva disciplinaria diversa, robusta y estimulante.

Palabras clave: Investigación de Turismo; Perfil; Temas; Tendencias.

\section{INTRODUÇÃO}

Nestas últimas décadas, o Turismo tem vindo a afirmar-se como um elemento importante da economia do serviços e um instrumento estratégico de apoio ao esforço de desenvolvimento de países e povos. Esta dinâmica levou a OMT (2001) a reconhecer a importância do papel da investigação neste domínio, por forma à compreensão dos eventos que se produzem neste sector, à explicação e preparação de informação sobre comportamentos, relações e tendências que ajudem ao entendimento do sistema turístico, à tomada de decisões e à construção de cenário e previsões sobre o seu futuro.

Para o seu adequado conhecimento vários autores têm vindo a sublinhar a importância do contributo de várias disciplinas, tendo em vista a sua complexa e múltipla realidade. Autores como Smith (1990) sublinham que o leque de problemas a investigar no turismo pode ser organizado tendo em atenção as várias formas de o analisar, quer como experiência humana com destaque para a análise de comportamentos interpessoais, quer nas suas vertentes sociológica, económica e geográfica, quer ainda nas dimensões empresariais ou de estrutura industrial. Outros, como Gunn (1994), chamam igualmente a atenção para outras disciplinas como o marketing, a história, a antropologia, a ciência política, ou mesmo a medicina, e a engenharia, todas elas a poderem contribuir com a sua investigação para um melhor conhecimento do turismo. Mais recentemente, Jafari (2005) vem acentuar a importância de o Turismo continuar como um domínio multidisciplinar de investigação, sublinhando que o "Tourism is more than economics, sociology, anthropology, psychology, and so on. Its study envolves them all, powering our ongoing scientification journey." (Jafari, 2005:2)

Em Portugal, a produção de conhecimento científico tem estado associada ao desenvolvimento dos cursos superiores em turismo, em particular na conclusão de teses de doutoramento e dissertações de mestrado e em projetos de investigação. Segundo Eurico (2011:78), a sua "distribuição cronológica permite-nos antever um crescimento exponencial da oferta de cursos de turismo desde os anos oitenta até ao corrente ano". Como sublinha ainda esta autora, de 2007 a 2011, foram disponibilizadas 12101 vagas em cursos superiores de Turismo em Portugal.

Em 2009, Silva, Rodrigues, Mendes e Pereira publicam um estudo onde, a par de informação sobre as teses e dissertações em Turismo em Portugal, comparam as temáticas abordadas nestes trabalhos com as necessidades das empresas e do sector público, tendo por objectivo a contribuição para uma agenda de investigação em Portugal. O trabalho que agora se apresenta é um primeiro contributo para se conhecer o perfil do investigador português na área 
do Turismo e os temas que são objecto de investigação. Os resultados mostram uma comunidade científica predominantemente jovem e em crescimento e sublinham igualmente uma diversa, sólida e estimulante perspectiva disciplinar.

\section{METODOLOGIA}

\subsection{Instrumento de recolha de dados}

O presente trabalho foi preparado por solicitação da International Academy for the Study of Tourism que considerou de interesse incluir na sua 13a conferência (organizada pela Universidade do Algarve e que decorreu entre 2 e 7 de junho, 2013), e mais especificamente no painel Tourism Research Trends, uma apresentação da situação portuguesa face à investigação em Turismo, focada nas principais características dos investigadores e da investigação realizada. Esta apresentação traduzir-se-ia numa comunicação oral, não publicada, nesta conferência.

Perante este desafio e tendo por base os indicadores habitualmente usados para aferir a qualidade da investigação dos membros integrados em centros de investigação financiados pela Fundação para a Ciência e Tecnologia (FCT), em Portugal, plasmados nas designadas tabelas de produtividade, foi possível desenhar um questionário que permitisse uma aproximação da realidade portuguesa no que concerne a esta temática, estruturado em torno de quatro blocos.

O bloco 1, intitulado "Caracterização do Investigador", incluía questões, por exemplo, sobre se o investigador leciona no Ensino Superior, em que subsistema (Universitário versus Politécnico), instituição, cargo ocupado, grau académico mais elevado e afiliação ou não num centro de investigação. O bloco 2, designado por "Caracterização da Investigação", questionava, nomeadamente, sobre a percentagem de tempo que dedica à investigação e à investigação em Turismo em particular, participação em projetos de investigação (nacionais, internacionais, financiados, não financiados) e orientação de trabalhos de Investigação que tivessem como enfoque o Turismo (dissertações, teses ou outros). O bloco 3, intitulado "Caracterização das Publicações do Investigador", visava conhecer, principalmente, o número de livros, capítulos de livros ou artigos de índole científica, intenção de continuidade na investigação em Turismo no futuro, temáticas a investigar e número de trabalhos científicos submetidos. A listagem de temáticas a incluir no questionário assentou numa tentativa de sistematização de possíveis áreas, tendo por base os trabalhos de Ballantyne et al. (2009), Cheng et al.( 2011), Ma e Law (2009), Park et al. (2011), Tian e Lee (2011) e Xiao e Smith (2006). Estes trabalhos não partilhavam a mesma listagem de possíveis temáticas. A listagem final das áreas a incluir no questionário resultou então da identificação de áreas consensuais nos vários trabalhos ou listadas em pelo menos dois deles, a saber: "Educação e formação em turismo", "Imagem e marca do destino", "Eventos", "Turismo e Residentes", Comportamento do consumidor", "Governança e política do turismo", "Turismo e Ambiente", "Desenvolvimento do turismo enquanto área de conhecimento", "Geografia do 
turismo", "Gestão de organizações turísticas", "Turismo e transportes", "Turismo e sistemas de informação" e "Planeamento e gestão de destinos turísticos". Para além destas temáticas, incluíram-se ainda as relativas aos produtos turísticos específicos referidos no Plano Estratégico Nacional do Turismo (PENT) (Turismo de Portugal, 2007): "Turismo cultural", "Turismo desportivo", "Turismo gastronómico", "Turismo e golfe", "Turismo de natureza", "Turismo náutico", "Turismo de negócios", "Turismo residencial e resorts integrados", "Turismo de rural", "Turismo de saúde e bem estar", "Turismo de sol e mar". Por fim, o bloco 4, "Perfil do Investigador" procurava uma caracterização do mesmo por género e idade.

Em suma, a relevância do instrumento usado reflete a forma como os investigadores e a investigação científica é aferida, no caso português, por centros de investigação financiados pela FCT e também por contemplar as temáticas de investigação identificadas na literatura científica específica, acima referenciadas, bem como as respeitantes aos produtos turísticos considerados estratégicos no contexto nacional.

\subsection{População inquirida e amostra}

Dado que não existia uma base de amostragem com a identificação do conjunto de investigadores em Turismo em Portugal, usou-se como ponto de partida os investigadores da Rede de Investigação e Educação de Turismo da Lusofonia (RIETL) a quem foi pedido que identificassem todos os colegas que conhecessem e que investigassem na área do Turismo. Este procedimento decorreu durante o mês de março e permitiu identificar 166 investigadores, 50.9\% do género feminino e $49.1 \%$ do masculino, provenientes de várias Instituições de Ensino Superior. 0 questionário online foi então enviado a estes investigadores, tendo sido possível obter 111 respostas válidas, que correspondem a $66.9 \%$ da população inquirida (Tabela 1).

Tabela 1 - População inquirida e amostra

\begin{tabular}{lcc}
\hline Instituições de Ensino Superior* & População Inquirida & Amostra \\
\hline Escola Superior de Hotelaria e Turismo do Estoril & $26(15.7 \%)$ & $10(9.0 \%)$ \\
Instituto Politécnico de Bragança & $5(3 \%)$ & $5(4.5 \%)$ \\
Instituto Politécnico de Leiria & $23(13.9 \%)$ & $14(12.6 \%)$ \\
Universidade de Aveiro & $9(5.4 \%)$ & $3(2.7 \%)$ \\
Universidade de Coimbra & $6(3.6 \%)$ & $2(1.8 \%)$ \\
Universidade de Lisboa & $9(5.4 \%)$ & $5(4.5 \%)$ \\
Universidade do Algarve & $30(18.1 \%)$ & $25(22.5 \%)$ \\
Universidade dos Açores & $9(5.4 \%)$ & $2(1.8 \%)$ \\
Universidade Lusófona & $6(3.6 \%)$ & $6(5.4 \%)$ \\
Outra & $43(25.9 \%)$ & $39(35.1 \%)$ \\
\hline Total & $166(100.0 \%)$ & $111(100 \%)$ \\
*Foram recebidas respostas relativamente a 30 instituições. A tabela detalha as instituições onde foi possível identificar \\
pelo menos 5 investigadores em Turismo. \\
Fonte: Elaboração própria (2013).
\end{tabular}


Muito embora a amostra contemple $66.9 \%$ dos investigadores da população inquirida, o tabela 1 mostra que a sua distribuição pelas diferentes instituições de Ensino Superior não é igual à que se verifica na população inquirida. Com efeito, e para assegurar uma repartição mais próxima entre população inquirida e amostra teria sido desejável que mais investigadores de algumas instituições tivessem preenchido o questionário. $O$ facto de se conhecer a origem das respostas obtidas permite concluir, todavia, que os investigadores que, conhecidamente, mais investigam em Turismo em Portugal, responderam ao questionário. O trabalho prossegue apresentando os principais resultados da análise dos dados provenientes da amostra obtida. Dada a não aleatoriedade da mesma, o tratamento estatístico é descritivo, não sendo estabelecida qualquer extrapolação para o universo em estudo. Muito embora outros cruzamentos pudessem ter sido estabelecidos, apresentam-se neste trabalho aqueles que se considerou terem interesse numa publicação de âmbito internacional.

\section{RESULTADOS}

\subsection{Perfil do investigador}

Da aplicação do questionário resultaram 111 respostas válidas cuja análise passamos a apresentar. Tal como a população inquirida, a amostra inclui mais investigadores do género feminino (52.3\%) do que do masculino (47.7\%). As idades variam entre os 30 e os 78 anos, sendo a média de 46.5 anos (com um desvio padrão de 9.1 anos). A idade mediana ronda os 45 anos. A Tabela 2 mostra que as investigadoras inquiridas são, em média, mais jovens do que os investigadores (43.4 anos versus 49.39 anos). A reforçar este resultado, note-se que cerca $40 \%$ das investigadoras têm menos de 40 anos ao passo que 34\% dos investigadores possuem 51 anos ou mais.

Tabela 2 - Distribuição da idade por género

\begin{tabular}{ccc}
\hline \multirow{2}{*}{$\begin{array}{c}\text { Idade } \\
\text { (anos) }\end{array}$} & \multicolumn{2}{c}{ Género } \\
\cline { 2 - 3 }$<=40$ & $39.7 \%$ & Masculino \\
$41-50$ & $43.1 \%$ & $11.3 \%$ \\
$51-60$ & $13.8 \%$ & $54.7 \%$ \\
$61+$ & $3.4 \%$ & $28.3 \%$ \\
\hline Total & $100.0 \%$ & $5.7 \%$ \\
\hline Média & 43.40 & $100.0 \%$ \\
\hline
\end{tabular}

Fonte: Elaboração própria (2013).

A tabela 3 mostra a distribuição dos investigadores atendendo à sua qualificação 
académica e enquadramento num centro de investigação. Da leitura dos dados destaca-se o elevado nível académico dos investigadores respondentes, $80.2 \%$ dos quais detentor do grau de Doutor. De destacar também que $95.5 \%$ dos investigadores que possuem o grau de Licenciado ou de Mestre encontram-se em fase de conclusão do seu doutoramento. De notar, todavia, a multiplicidade de áreas de doutoramento destes investigadores, sobretudo na Economia ou Gestão (38.2\%) mas também na Geografia (19.1\%). Apenas 31.5\% dos inquiridos refere ser doutorado em Turismo. Outro resultado de interesse prende-se com o número importante de investigadores afiliados em centros de investigação (80.5\%), 78\% dos quais a desenvolver a sua atividade numa linha de investigação em Turismo.

A generalidade dos investigadores inquiridos, $94.7 \%$, é docente numa instituição de ensino superior (IES). Destes, a maior parte leciona num instituto politécnico (55.8\%) e a grande maioria em cursos de Turismo (86\%). Sobre o grau de ensino em que decorre o serviço docente, destacase o 1 ㅇ ciclo de estudos em que $65.4 \%$ dos inquiridos refere colaborar. De notar que a maioria destes investigadores leciona em cursos de mestrado (57.7\%) e uma parcela, com algum peso (20.7\%), leciona também em programas de doutoramento em Turismo. Destas colaborações ao nível dos segundos e terceiros ciclos decorrem várias orientações de dissertações de mestrado e de teses de doutoramento, referidas por $60.4 \%$ dos investigadores respondentes.

Tabela 3 - Qualificações acadêmicas e afiliação

\begin{tabular}{ll}
\hline Grau académico & Doutoramento: $80.2 \%$ \\
& Mestrado: $16.2 \%$ \\
& Licenciatura: $3.6 \%$ \\
\hline Área do doutoramento & Turismo: $31.5 \%$ \\
& Geografia: $19.1 \%$ \\
& Economia ou Gestão: 38.2\% \\
& Outra: 11.2\% \\
\hline Afiliação num centro de & Afiliado: $80.5 \%$ \\
investigação & Não Afiliado: $19.5 \%$ \\
\hline Fonte: Elaboração própria (2013). &
\end{tabular}

\subsection{Caracterização da investigação}

\subsubsection{Tempo dedicado à investigação em Turismo}

Um primeiro olhar recaiu sobre o tempo dedicado à investigação em Turismo. A este respeito os investigadores inquiridos referem que, em média, cerca de metade do tempo que dedicam à investigação (46.7\%) é reservado à temática do Turismo. Estes resultados não obstam a que exista um número importante de investigadores a dedicar a generalidade do seu tempo de investigação ao Turismo. Como mostra a figura 1, $21.8 \%$ dos inquiridos dedica mais de $80 \%$ do seu 
tempo de investigação à área do Turismo.

Muito embora, como vimos, as investigadoras inquiridas sejam, em média, mais jovens que os investigadores, verifica-se que são estes últimos que, em média, dedicam uma percentagem maior de tempo à investigação em turismo (percentagem de tempo médio dedicado à investigação em Turismo entre os investigadores: 49.89\%; idem entre as investigadoras: $43.4 \%$ ). Numa análise por grupo etário, a Figura 2 evidencia que é entre os investigadores com idade compreendida entre os 41 e os 50 anos que se encontra uma proporção maior de tempo de investigação nas temáticas do Turismo (48.91\%).

Figura 1 -Percentagem de tempo dedicada à investigação em Turismo

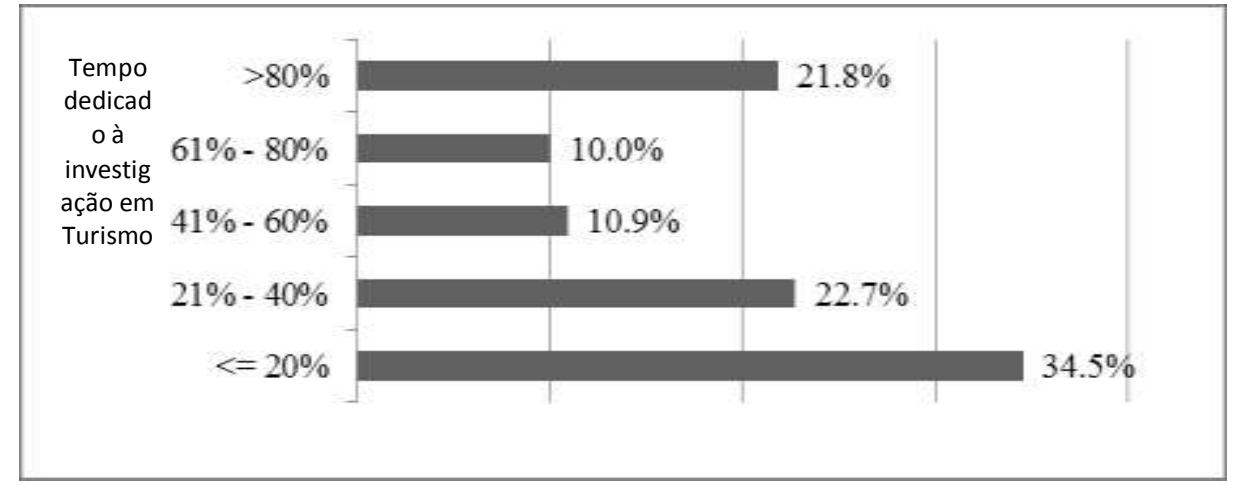

Fonte: Elaboração própria (2013).

Figura 2 - Percentagem de tempo dedicada à investigação em Turismo por grupo etário

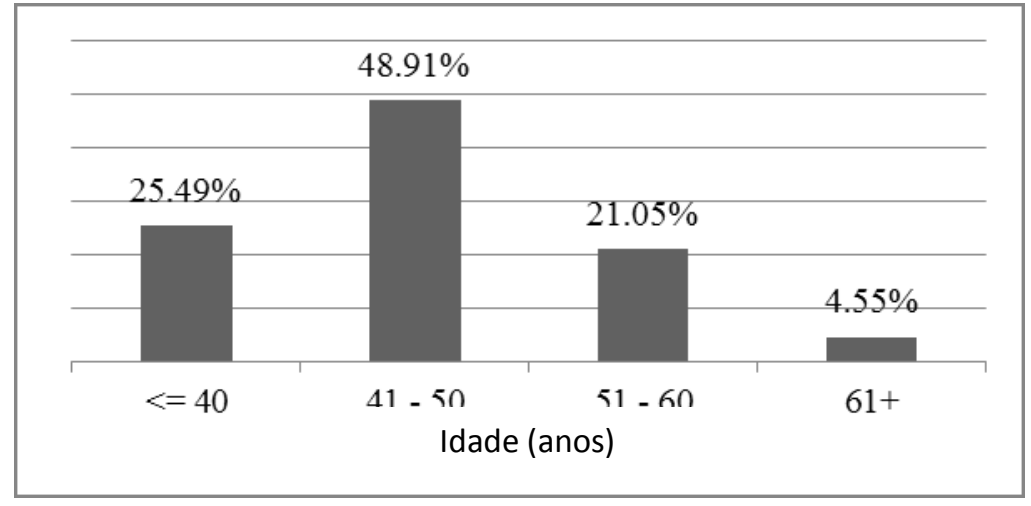

Fonte: Elaboração própria (2013).

Esta repartição de tempo de investigação entre o Turismo e outros domínios do conhecimento era expetável dada a diversidade de áreas de doutoramento dos investigadores, a maioria de Economia, Gestão ou Geografia. No entanto, como mostra a Figura 3, é entre os investigadores com doutoramento em Turismo que se regista uma percentagem maior de tempo médio afeto à investigação nesta área (51.9\%). 
Figura 3 - Percentagem de tempo dedicada à investigação em Turismo por área do doutoramento

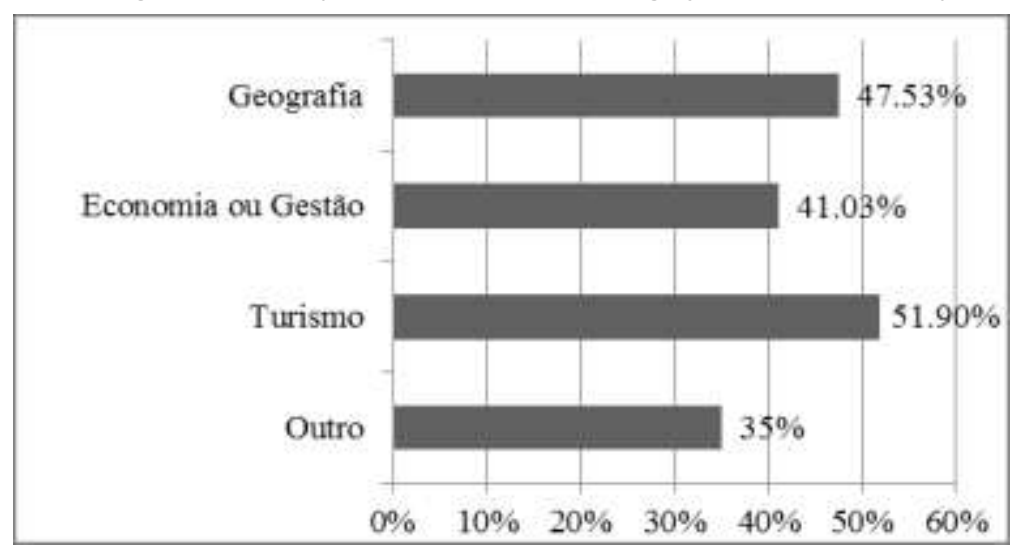

Fonte: Elaboração própria (2013).

\subsubsection{Interesses e Resultados da Investigação}

Um aspecto com particular interesse neste estudo prendia-se com a identificação das temáticas específicas que despertam maior interesse nos investigadores. Com base nas respostas obtidas foi possivel identificar as 10 temáticas que têm merecido mais atenção em termos de investigação e, entre estas, as três a que os investigadores mais se têm dedicado. Estes resultados encontram-se na Figura 4 que deixa clara a relevância das temáticas "comportamento do consumidor", "imagem e marca dos destinos" e "governança e política de turismo", apontadas como áreas de investigação por $45.9 \%, 36.4 \%$ e $28.8 \%$ dos inquiridos, respetivamente. O peso atribuído a estas temáticas, que muito se inserem na área da Gestão, sobretudo no domínio do Marketing, não é um resultado inesperado atendendo à área dominante de doutoramento dos investigadores analisados (Economia ou Gestão).

Figura 4 - Temáticas de investigação em Turismo

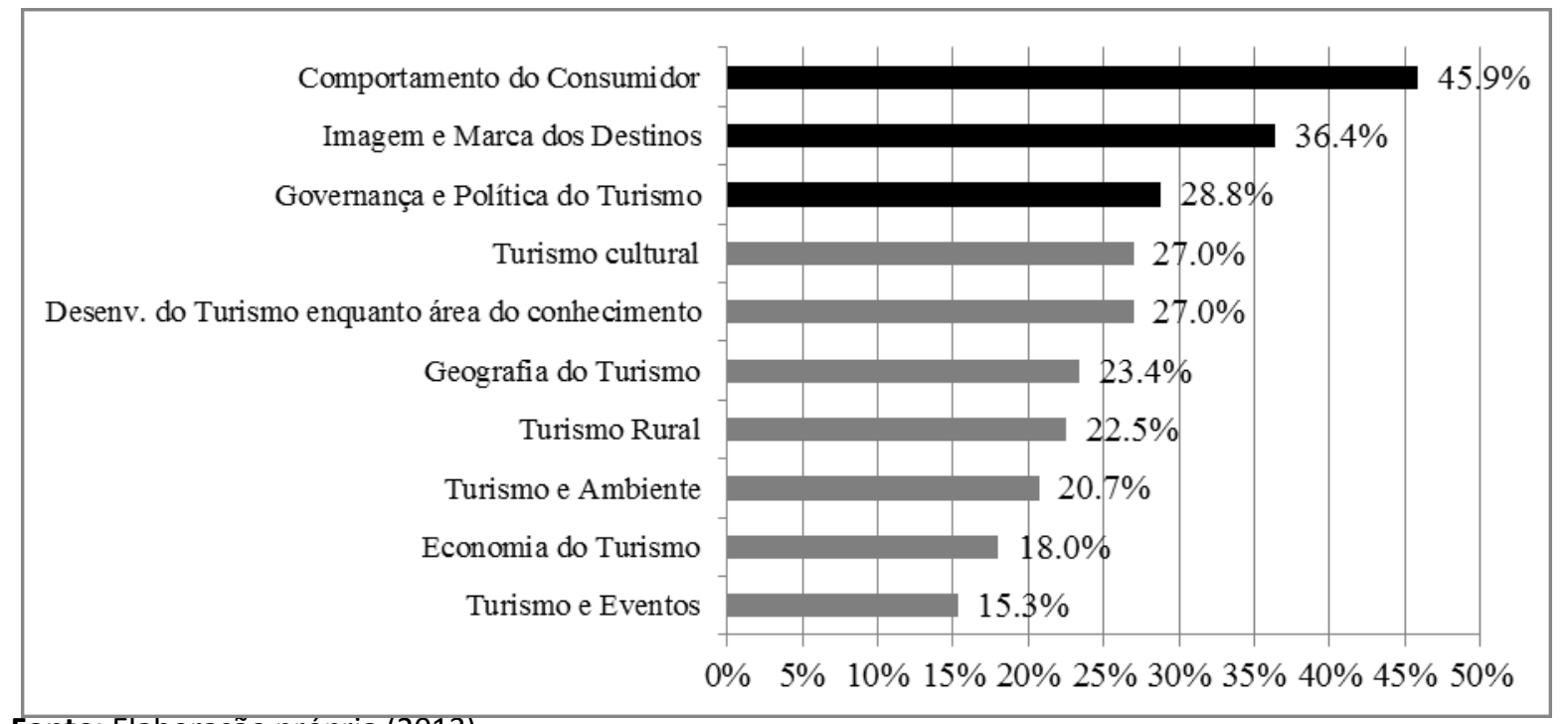

Fonte: Elaboração própria (2013). 
As temáticas em investigação também apresentam diferenças se observadas consoante a área de doutoramento do investigador (Tabela 4). Nesta análise importa destacar as temáticas que melhor diferenciam os três grupos por serem especificamente mais objeto de atenção em cada um. Neste sentido, destaca-se o interesse pela "educação e formação em turismo" entre os doutorados em Turismo, a temática da "economia do turismo" entre os doutorados em Economia ou Gestão e a relevância clara das temáticas da "geografia do turismo" e do "turismo cultural" entre os doutorados em Geografia.

\begin{tabular}{ll} 
Tabela 4 - Temáticas de investigação em Turismo por área do doutoramento \\
\hline Doutorados em Turismo & Comportamento do Consumidor: $53.6 \%$ \\
& Imagem e Marca dos Destinos: $42.9 \%$ \\
& Governança e Política do Turismo: $32.1 \%$ \\
& Educação e Formação em Turismo: $28.6 \%$ \\
\hline Doutorados em Economia ou & Comportamento do Consumidor: $61.8 \%$ \\
Gestão & Imagem e Marca dos Destinos: $35.3 \%$ \\
& Desenvolvimento do Turismo enquanto área do \\
& conhecimento: $32.4 \%$ \\
& Economia do Turismo: $29.4 \%$ \\
\hline Doutorados em Geografia & Geografia do Turismo: $70.6 \%$ \\
& Turismo Cultural: $58.8 \%$ \\
& Governança e Política do Turismo: $41.4 \%$ \\
& Turismo de Natureza:41.2\%
\end{tabular}

Fonte: Elaboração própria (2013).

A Figura 5 mostra os resultados de investigação no horizonte temporal 2008-2012. Assim, neste período e com base nas respostas dos investigadores participantes neste estudo, foi possível contabilizar um total de 902 publicações. Estes números, todavia, sobrevalorizam o total de publicações uma vez que, em trabalhos em coautoria, a mesma publicação é referida por mais do que um autor. Assim, mais importante do que o total registado é a sua distribuição por tipo de publicação e evolução no período em análise. Das 902 publicações referidas, 279 (31\%) são artigos científicos publicados em revistas indexadas, nacionais ou internacionais.

Figura 5 - Registros de produção científica (2008-2012)

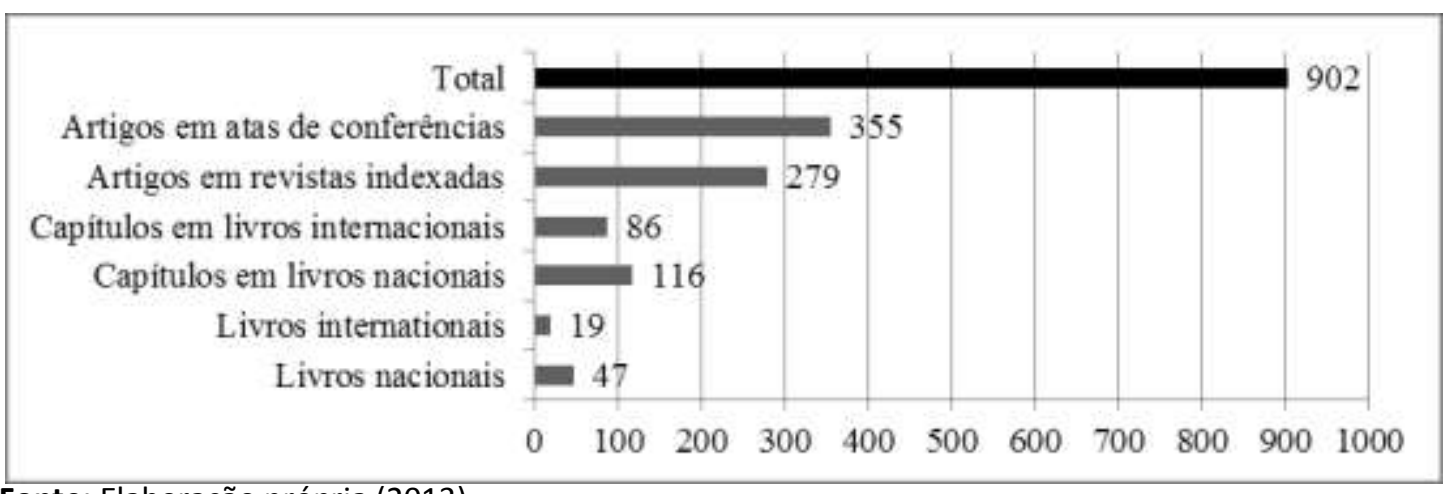

Fonte: Elaboração própria (2013). 
Neste contexto, torna-se mais relevante observar a evolução das publicações ao longo do tempo. A Figura 6 mostra assim a evolução dos artigos científicos publicados em revistas indexadas no período objeto de análise, revelando uma tendência claramente crescente a partir 2009.

Figura 6 - Evolução do peso do no de artigos em revistas indexadas no total da produção científica

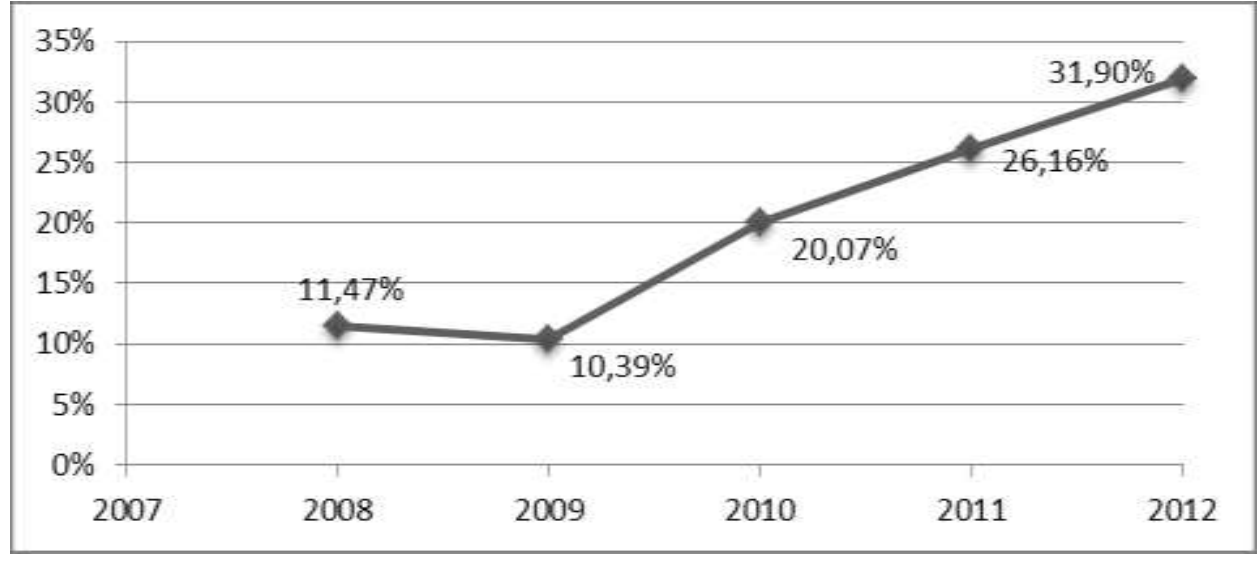

Fonte: Elaboração própria (2013).

\subsubsection{Projetos da Investigação}

Cerca de metade (51.4\%) dos investigadores participantes no estudo encontra-se a desenvolver projetos de investigação na área do Turismo. Destes investigadores, $41.4 \%$ refere estar a participar em projetos de âmbito nacional, apenas $24.3 \%$ objeto de financiamento. Dos investigadores com projetos, apenas $24.3 \%$ participa em projetos internacionais. Neste último caso, a grande maioria dos projetos, $70.2 \%$, é financiado.

Tabela 5 - Projetos de investigação em Turismo por área do doutoramento

\begin{tabular}{ll}
\hline Doutorados em Turismo & Investigadores com projetos em Turismo: $67.9 \%$ \\
& Investigadores a participar em projetos nacionais: $57.1 \%$ \\
& Investigadores a participar em projetos nacionais financiados: $37.5 \%$ \\
& Investigadores a participar em projetos internacionais: $28.6 \%$ \\
& Investigadores a participar em projetos internacionais financiados: $62.5 \%$ \\
\hline Doutorados em Economia & Investigadores com projetos em Turismo: $58.8 \%$ \\
& Investigadores a participar em projetos nacionais: $57.9 \%$ \\
& Investigadores a participar em projetos nacionais financiados: $44.4 \%$ \\
& Investigadores a participar em projetos internacionais: $26.5 \%$ \\
& Investigadores a participar em projetos internacionais financiados: $66.7 \%$ \\
\hline Doutorados em Geografia & Investigadores com projetos em Turismo: $52.9 \%$ \\
& Investigadores a participar em projetos nacionais: $41.2 \%$ \\
& Investigadores a participar em projetos nacionais financiados: $57.1 \%$ \\
& Investigadores a participar em projetos internacionais: $29.4 \%$ \\
& Investigadores a participar em projetos internacionais financiados: \\
& $100.0 \%$
\end{tabular}

Fonte: Elaboração própria (2013). 
Numa análise segundo a área de doutoramento, a tabela 5 mostra que é entre os doutorados em Turismo que se regista uma proporção maior de projetos de investigação (67.9\%), seguindo-se os doutorados em Economia ou Gestão (58.8\%) e, por último, os doutores em Geografia (52.9\%). No entanto, é neste último grupo que se denota uma percentagem superior de projetos financiados, nacionais e internacionais. Este aspecto pode dever-se ao facto da área do Turismo não constar, por exemplo, na classificação de áreas científicas da Fundação para a Ciência e a Tecnologia, o que conduz a que muitos projectos seja classificados na área da Geografia. Neste caso, naturalmente, os investigadores com doutoramento nesta área estarão em melhores condições de submeter projectos melhor fundamentados neste domínio científico.

\subsubsection{Tendências da Investigação}

Um primeiro resultado que importa ressaltar prende-se com a intenção manifestada pela generalidade dos investigadores inquiridos (96.4\%) em continuar a desenvolver a sua atividade de investigação na área do Turismo. Por áreas de doutoramento, esta intenção é de $100 \%$ entre os investigadores doutorados em Geografia, $96.4 \%$ entre os doutores em Turismo e, numa proporção mais baixa, 91.2\%, entre os investigadores em Economia ou Gestão.

Igualmente de destacar, na Figura 7, a comparação entre o número de publicações no período 2008-2012 (barras a cinza escuro) e o número de trabalho submetidos para publicação em 2013 (barras a cinza claro). Muito embora, e mais uma vez, os valores absolutos encontrados nos vários itens analisados estejam subavaliados pelo facto da mesma publicação poder ser referida pelos vários coautores, a comparação entre os dois tipos de barras mostra bem o dinamismo e a atenção que a área do Turismo está a merecer na atualidade, em que as barras a verde, que representam a investigação atual, representam cerca de $1 / 3$ das barras a cinza, que representam a investigação nos últimos cinco anos.

Figura 7 - Registros de produção científica (2008-2012) e submissões em 2013

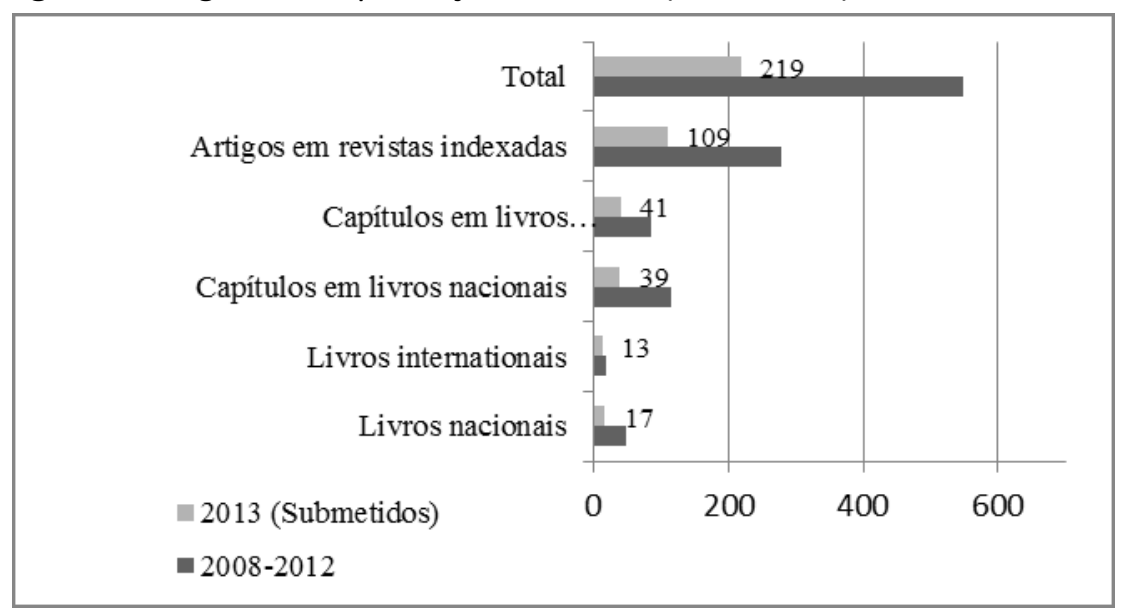

Fonte: Elaboração própria (2013). 
A Figura 8 mostra as temáticas em que, no futuro, os investigadores inquiridos pretendem desenvolver. Mais uma vez, as temáticas "comportamento do consumidor", "imagem e marca dos destinos" e "governança e políticas de turismo" destacam-se nas preferências dos investigadores, muito embora estas duas últimas percam alguma expressão quando comparadas com o peso que têm na atualidade (Figura 4). Em contrapartida, uma quarta temática surge igualmente em terceiro lugar nas intenções de investigação, a saber o desenvolvimento do Turismo nos seus aspetos mais teóricos e conceptuais.

Figura 8 - Temáticas de investigação a desenvolver

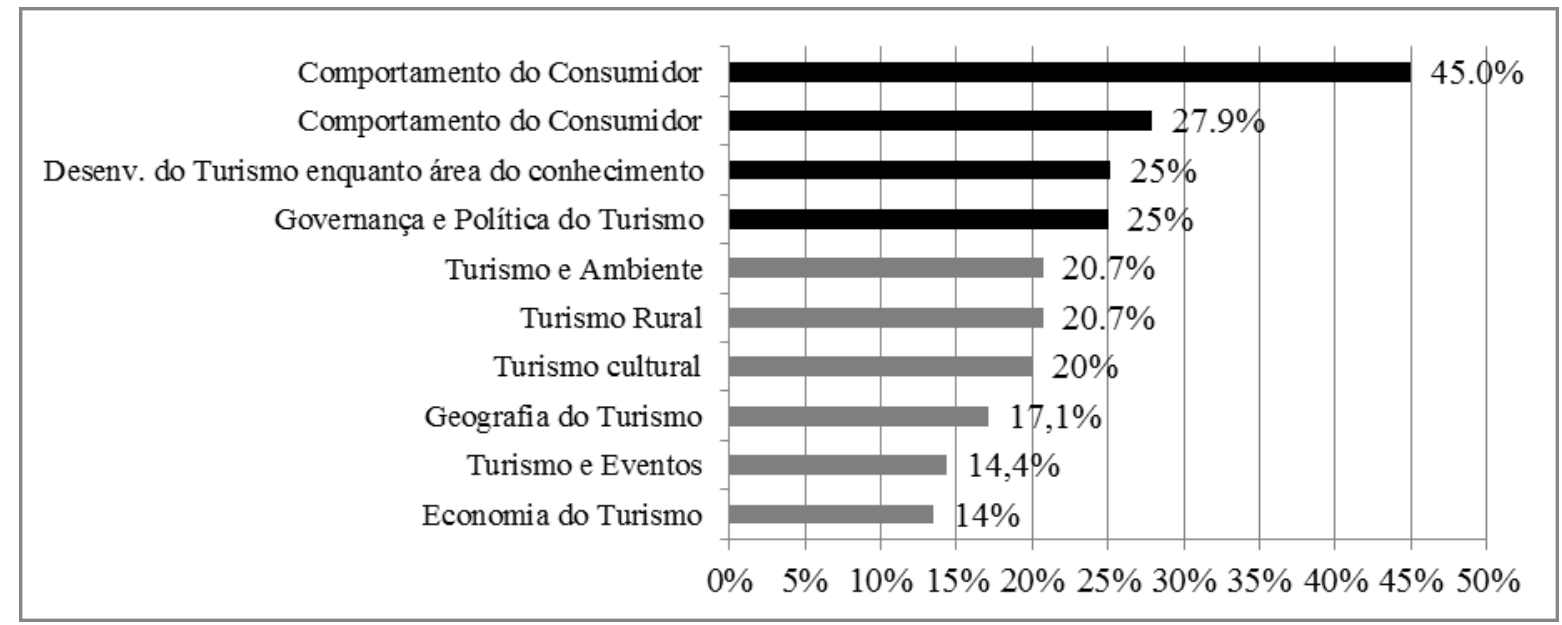

Fonte: Elaboração própria (2013).

\section{CONCLUSÕES}

O presente trabalho visou, em primeiro lugar, proporcionar um contributo para o conhecimento do perfil do investigador português na área do Turismo. A este respeito, a análise dos dados revelou uma ligeira predominância do género feminino, uma média de idades aproximada de 46 anos e um nível de qualificações elevado, com cerca de $80 \%$ dos investigadores a deter o grau de doutor e afiliado num centro de investigação. Entre as áreas de doutoramento destacam-se a Economia ou a Gestão (38.2\%), o Turismo (31.5\%) e a Geografia (19.1\%). A quase generalidade dos investigadores leciona numa instituição de ensino superior e cerca de $20 \%$ colabora também em programas de doutoramento em Turismo. Mais de metade orienta dissertações de mestrado e de teses de doutoramento.

Em segundo lugar, o estudo procurou aproximar as características da investigação realizada. A este respeito, e para os investigadores analisados, verificou-se que cerca de metade do tempo reservado à investigação é dedicado à temática do Turismo, sendo entre o género masculino, no grupo etário dos 41 aos 50 anos e entre os investigadores com doutoramento em 
Turismo que se registam tempos médios superiores de dedicação a esta área. Entre as principais temáticas de investigação destacam-se o "comportamento do consumidor", a "imagem e marca dos destinos" e a "governança e política de turismo", ou seja, temáticas que se podem enquadrar na área da Gestão, principalmente no domínio do Marketing.

Mais do que o total de publicações apurado, importa destacar que cerca de $1 / 3$ correspondem a artigos científicos publicados em revistas indexadas, nacionais ou internacionais, cujo número tem registado um crescimento notório a partir 2009. O dinamismo da investigação em Turismo manifesta-se também na participação em projectos de investigação, indicada por cerca de metade dos participantes no estudo, sobretudo em projetos nacionais e, já com alguma expressão, em projetos internacionais. Nesta análise foi interessante verificar que é entre os doutorados em Turismo que se denota uma percentagem maior de projetos de investigação. Todavia, é entre os doutorados em Geografia que se regista denota uma proporção superior de projetos financiados, nacionais e internacionais.

Os resultados deste trabalho sugerem um futuro promissor para a investigação em Turismo em Portugal. Com efeito, a generalidade dos investigadores, independentemente da sua área de doutoramento, manifesta a intenção de continuar a trabalhar neste domínio científico. A acrescentar a este aspecto, refira-se que o número de trabalhos científicos submetidos em Março de 2013, altura em que o questionário foi aplicado, já representava cerca de $1 / 3$ de toda a produção científica efetuada nos últimos cinco anos. A interdisciplinaridade deste domínio científico revela-se, mais uma vez, na diversidade de temáticas a investigar no futuro, lideradas pelo "comportamento do consumidor" a que se segue a "imagem e marca dos destinos", a "governança e políticas de turismo" e o "desenvolvimento do Turismo enquanto área do conhecimento".

Muito embora, como referido, os investigadores que, conhecidamente, mais investigam em Turismo em Portugal tenham acedido a participar no estudo, teria sido desejável uma repartição mais próxima entre população inquirida e amostra e que mais investigadores de algumas instituições tivessem preenchido o questionário. Neste contexto e como proposta de investigação futura, seria interessante replicar o estudo classificando a população alvo de investigadores atendendo à IES em que se inserem e ao "volume/nível" de produção científica que desenvolvem, aspecto este que teria de ser objetivamente definido. Num segundo momento poder-se-ia definir uma amostra aleatória de investigadores que refletisse a sua distribuição por IES e produção científica. Tal não será difícil de conseguir numa situação em que mais tempo exista para desenvolver um estudo desta natureza e, em particular, para prolongar o período de recolha de dados, alterando, eventualmente, a forma de obtenção dos mesmos. Certamente que um contacto mais pessoal, que um inquérito online não permite, poderá contribuir para obter mais respostas. 


\section{REFERÊNCIAS}

Ballantyne, R., J. Packer e M. Axelsen (2009). Trends in Tourism Research. Annals of Tourism Research, 36 (1), pp.149-152.

Cheng, C.K., X. Li., J.F. Petrick e J.T. O'Leary (2011). An Examination of Tourism Journal Development. Tourism Management, 32 (1), pp.53-61.

Eurico, S.T. (2011). Ensino Superior em turismo: satisfação e empregabilidade. Tese de Doutoramento, Faculdade de Economia, Universidade do Algarve.

Gunn, C.L. (1994). Perspective on the Purpose and Nature of Tourism Research Methods, Travel in Tourism and Hospitality Research: A Handbook for Managers and Researchers, J. R. B. Ritchie e C. R. Goeldner (Eds), New York, JohnWiley and Sons, pp. 3-9.

Jafari, J. (2005). Bridging Out, Nesting Afield: Powering a new Platform, The Journal Of Tourism Studies. 16(2), pp. 1-5.

Ma, J. e R. Law (2009). Components of Tourism Research. Evidence from Annals of Tourism Research, Anatolia. 20 (1), pp. 62-74.

Organización Mundial del Turismo (2001). Apuntes de Metodologia de la Investigación en turismo. Madrid.

Park, K., W. J. Phillips, D. D. Canter e J. Abbott (2011). Hospitality and Tourism Research Rankings by Author, University, and Millennium. Journal of Hospitality \& Tourism Research, 35 (14), pp.381-416.

Smith, S. (1999). Toward a National Tourism Research Agenda for Canadá. Tourism Management, 20, pp. 297-304.

Silva, J.A., P. Rodrigues, J. Mendes e L. Pereira (2009). A Tourism Research Agenda for Portugal, International Journal of Tourism Research. 12 (1), pp. 90-101.

Tian, Y. e H. Lee (2011). A Comparison of Research Topics in Leading Tourism Journals. International Journal of Tourism Sciences, 11(3), pp. 108-126.

Turismo de Portugal (2007). Plano Estratégico Nacional do Turismo (PENT). Disponível em http://www.turismodeportugal.pt/Portugu\%C3\%AAs/turismodeportugal/Documents/PENT_Revis\%C3\%A3o .pdf.

Xiao, X. e S.L.J. Smith (2006). The Making of Tourism Research: Insights from a Social Sciences Journal. Annals of Tourism Research, 33(2), pp. 490-50. 